\title{
La construcción del género en el franquismo y los discursos educativos de la Sección Femenina
}

\author{
Rabazas Romero, Teresa \\ Ramos Zamora, Sara \\ Universidad Complutense de Madrid
}

\section{ABSTRACT}

In this paper we consider gender as a category of analysis to study the educational speeches that the "Sección Femenina" (political organization for women) addressed to women during Franco's dictatorship. Following the new approaches of contemporary historiography that requires another type of sources and methods our analysis focuses in the feminine magazine "Consigna". This publication was the vehicle that the "Sección Femenina" used to spread their educational slogans, that is to say, the way that this pro-Franco institution was dedicated to the indoctrination of women, especially female teachers, due to their multiplying influence in education circles.

Key words: Gender, Franco's dictatorship, "Sección Femenina", women, education, female teachers.

\section{RESUMEN}

En nuestro estudio consideramos el género como una categoría de análisis para examinar los discursos educativos que la Sección Femenina dirigió a las mujeres durante el franquismo. En este sentido, y de acuerdo con los nuevos enfoques de la historiografía contemporánea que requiere otro tipo de fuentes y métodos, nos ha interesado analizar la revista femenina "Consigna" por tratarse de un vehículo propagador de los discursos educativos trasmitidos por la Sección Femenina, organismo adoctrinador del régimen franquista en lo que se refiere a la transmisión de valores dirigidos a las mujeres $\mathrm{y}$, de forma muy especial, a las maestras por su efecto multiplicador y propagador.

Descriptores: Género, franquismo, Sección Femenina, mujeres, educación, maestras.

\section{RÉSUMÉ}

Dans ce papier nous considérons le genre (sexe) comme une catégorie d'analyze pour examiner les discours éducatifs que la "Sección Feminina» (l'organisation politique pour femmes) adressait aux femmes sous la dictature de Franco. En suivant les nouvelles approches de l'historiographie, qui requiert un autre type de sources et de méthodes, notre analyse se concentre sur la revue féminine "Consigna.» Cette publication servait de vehicule à la "Sección Feminina» pour répandre leurs slogans éducatifs, c’est-à-dire, l'avenue utilisée par de telles institutions pro-Franco pour endoctriner les femmes, surtout les enseignantes, à cause de leur effet multiplicateur.

Mots-clés: le genre (sexe), la dictature de Franco, "La Section Féminine», les femmes, l'éducation, les enseignantes 


\section{Introducción}

$\mathrm{L}$ AS NUEVAS TENDENCIAS EN historiografía educativa demandan cada vez más revisiones críticas de nuestra historia. La intención es desvelar o desentrañar los silencios producidos en algunos momentos de la historia educativa de nuestro país. Durante las dos últimas décadas han proliferado numerosos estudios en torno a nuestra historia más reciente. Son diferentes factores los que han provocado la autocensura de estudiar ciertas épocas de nuestro pasado: "Autocensura previa que impidió muchos trabajos entonces, y que después, como hábito negativo que era, ha contribuido a forjar esos silencios de época en historiadores de la educación, y, lo que es peor, a crear una inercia para mantener silencios que nada tenían que ver con un régimen determinado.” (Ruiz Berrio, 2000, p. 277).

Sin embargo, aunque son todavía muchos los silencios de la Historia de la Educación, las nuevas formas de hacer una historia cultural nos plantean nuevas posibilidades y enfoques en la comprensión de la historia. El sentido de la historia cultural, según Burke, "debe contener en sí mismo una variedad de lenguas y puntos de vista de los vencedores y de los vencidos, de los hombres y de las mujeres, de los propios y de los extraños, de los contemporáneos y de los historiadores”(2000, p. 264). La propuesta del autor nos parece muy interesante porque permite acercarse a la reconstrucción de la historia, sin prejuzgar la superioridad o inferioridad de las culturas, sino desde el reconocimiento de su diferencia.

Junto a los silencios mencionados más arriba, tienen para nosotras especial interés los estudios de género. Tal y como lo señala Burke en una de sus últimas publicaciones, la historia cultural pone "el énfasis en las culturas como totalidades ofrece un remedio para la actual fragmentación de la disciplina en especialistas en la historia de la población, la diplomacia, las mujeres, las ideas, los negocios, la guerra, etc." (2005, pp. 13-14)

Hasta los años ochenta, en España no aparecen estudios sobre la mujer, siendo las últimas décadas del siglo XX el momento en que se incorporaron a todas las ciencias sociales. En esos años es cuando los estudios de género empezaron a surgir, introduciéndose a través del campo de la sociología de la familia o la sociología de la educación, y en el ámbito filosófico, con la obra Hacia una crítica de la razón pratriarcal, de la filósofa Celia Amorós, uno de los primeros textos feministas (Cobo Bedía, 1995, p. 56).

Cuando Simone de Beauvoir titulaba su libro El Segundo Sexo, "alegaba la tesis de la eterna sujeción femenina y su importancia secular. Al vivir en función del otro -el varón-, la mujer no tiene proyecto de vida propia, ha actuado siempre al servicio del patriarcado y, constituye el segundo sexo supeditado al sexo sujeto, protagonista activo y agente de la transformación histórica: el hombre". De esta manera, "toda la historia pasada ha sido obra del varón sin incidencia de la mujer” (Nash, 1984, p. 15). Este testimonio es una prueba más del vacío histórico que atañe a la mitad de la población: las mujeres. Las diversas corrientes historiográficas han marginado en sus estudios las aportaciones femeninas, apenas han reflejado su presencia en el acontecer histórico y no figuran como agentes de cambio histórico (Núñez y Rebollo, 2003, p. 232). 
El objetivo de nuestro trabajo se centra en la indagación y estudio de los modelos educativos dirigidos a las mujeres, que prevalecieron en los discursos imperantes en España a lo largo del franquismo. En este sentido, y de acuerdo con los nuevos enfoques de la historiografía contemporánea que requiere otro tipo de fuentes y métodos, nos ha interesado analizar la revista femenina "Consigna" por tratarse de un vehículo propagador de los discursos educativos trasmitidos por la Sección Femenina, organismo adoctrinador del régimen franquista en lo que se refiere a la transmisión de valores dirigidos a las mujeres $y$, de forma muy especial, a las maestras por su efecto multiplicador y propagador. ${ }^{1}$

\section{La construcción del género en la educación franquista}

Es importante delimitar el concepto de género que vamos manejar a lo largo de este trabajo. Según Ma Antonia Bel, en su libro titulado La historia de las mujeres desde los textos, conviene destacar que no es la realidad biopsicológica del sexo la que funda nuestras ideas culturales del género, sino la realidad cultural de los géneros la que ha determinado la idea de dos sexos naturales. La expresión "naturaleza humana" no ha significado lo mismo a lo largo de la historia. El punto de ruptura lo encontramos en la Ilustración. Mientras que antes de la Ilustración, y según el enfoque clásico, naturaleza humana era sinónimo de la plenitud humana, en el planteamiento ilustrado del S. XVIII se fija desde un funcionamiento presuntamente común a todos los hombres de todas las culturas. En consecuencia, mientras que en la perspectiva clásica la noción de naturaleza humana incluye la de cultura, la Ilustración tiende a oponerse (2000, pp. 14-15).

No cabe duda que el origen del concepto de género viene ligado a la teoría feminista y a las aportaciones de Simón de Beauvoir (2000). Compartiendo las ideas de la autora Rosa Cobo, si el género es una construcción cultural, y surge a partir de la idea de que lo femenino y lo masculino no son hechos naturales o biológicos, sino construcciones culturales, es incuestionable que ha de ser objeto de estudio de las ciencias sociales (1995, pp. 54-83). En estos estudios se mantiene la idea de que a lo largo de la historia, todas las sociedades se han construido a partir de las diferencias anatómicas entre los sexos, convirtiendo esa diferencia en desigualdad social y política. Culturalmente, lo femenino se ha definido siempre como una privación y defecto de lo masculino, en relación con la potencia, con su origen y con su forma (Ibidem, pp. 85-118). Al haber definido a las mujeres como naturaleza, se las ha excluido de la individualidad. En cambio, los hombres han sido conceptuados por la ideología patriarcal como individuos creadores de la cultura (Amoros, 1985, p. 48). Esa jerarquía entre lo femenino y lo masculino tiene importantes consecuencias dentro de la vida pública y privada de las mujeres y también entre otras, en la vida social, política, o educativa de un país. La más destacada, según señala la antropóloga Dolores Juliano, es que por un lado, se les niega la capacidad para elaborar una visión propia del mundo. Y por otro lado, se les asigna una cosmovisión (incluida una escala de valores y una tipificación de roles) que, aunque impuesta desde fuera, se pretende que sea percibida como generada en el seno del grupo dominado (1992, p. 44). 
Como señala el historiador británico Peter Burke la historia cultural ha propiciado estudios e investigaciones que dan lugar a revisiones críticas sobre el papel invisible de las mujeres en la historia o en los relatos históricos. En este sentido, la contribución del feminismo se considera un medio de recuperar a las mujeres como protagonistas de la historia cultural: "el feminismo, también ha tenido considerables implicaciones para la historia cultural, preocupada como ha estado por desenmascarar los prejuicios masculinos y por destacar la contribución femenina a la cultura, prácticamente invisible en el gran relato tradicional." (2005, p. 66)

En nuestro estudio consideramos el género como una categoría de análisis para determinar los discursos educativos que la Sección Femenina dirigió a las mujeres durante el franquismo. Pero dicho enfoque requiere una precisión conceptual debido al polémico debate surgido en la teoría feminista relativo al significado de la categoría de género. Destacamos la acertada conceptuación realizada recientemente por la profesora Miryam Carreño: "se considera el género como una construcción cultural con un marcado carácter histórico que le imprime modificaciones con relación a las condiciones de vida y al contexto económico, político y social concreto en el que se presenta” (2003-2004, p. 83). Desde esta perspectiva enfocamos este trabajo.

\section{Mujeres, educación y tradición en el primer franquismo}

El cambio social y político producido por el estallido de la Guerra Civil española (1936-1939), unido a los intereses políticos e ideológicos del Nuevo Régimen, inspirados en la ideología del nacional-catolicismo, trajo consigo una vuelta a la tradición educativa del Antiguo Régimen como ya lo han puesto de manifiesto numerosos estudios.

El contexto bélico de la Guerra Civil provocó un descenso de la población y una importante mortalidad infantil. De este modo, las mujeres estaban llamadas a transformar esa realidad social, contribuyendo a la renovación de la nueva España. La función de la mujer tenía un gran interés para el régimen franquista en lo que se refiere a su dedicación a la maternidad y al aprendizaje de normas sobre higiene y cuidado de los niños. El acceso a la enseñanza media y superior era inalcanzables para la gran mayoría de las mujeres en este período, aunque algunas profesiones vinculadas a esa función social, maestras, enfermeras, puericultoras, etc., eran recomendadas para un reducido sector femenino.

El nuevo modelo ideológico franquista se impone y se propaga en todas direcciones, pero sobre todo en el contexto educativo. La escuela, el profesorado y el libro de texto son utilizados para infiltrar los nuevos valores en la población infantil española. De forma especial cabe señalar la función social que estaba llamada a desempeñar la mujer en este nuevo régimen político. Las profesiones femeninas, que habían comenzado a asomar a la luz durante la Segunda República, se repliegan. La mujer que se convierte en la educadora de toda la familia y, sobre todo, de los hijos vuelve a ser educada únicamente con el propósito de convertirla en buena esposa y madre. "La mujer, por cuanto tiene encomendada una formación inicial en la vida del niño, por madre, necesita, para desempeñarla, de una preparación justa."(Consigna, 1941, no 17, p. 43). 
Se recomiendan las pautas de comportamiento cristianas, entre ellas, el sacramento del matrimonio y el papel dependiente de la esposa. Lo que viene a confirmar que imperaba un modelo educativo condicionado por las diferencias de orden biológico entre los sexos, consolidado en el siglo anterior ${ }^{2}$.

El franquismo supuso para la educación una vuelta a las ideas y a la pedagogía del diecinueve, dejando de lado las tendencias feministas de principios de siglo. El sentimiento patriótico-religioso, punto de partida de la ideología franquista, no constituía una novedad en el sistema educativo, si no que era ya ensalzado en los manuales de la Primera Restauración, donde se fomentaba la fidelidad a los principios de la ortodoxia religiosa como soporte de la conciencia nacional.

El modelo de sociedad que se transmitía era el de mantener una estructura social basada en los principios del siglo anterior, donde los valores fundamentales eran el servicio, la obediencia y la disciplina. La familia, por ende la mujer, es la célula esencial de este tipo de sociedad, porque se le asigna la misión de educar y transmitir unos valores tradicionales y conservadores destinados a perpetuar el orden social preestablecido: jerarquizado y autoritario. Los argumentos que se esgrimen a favor de la defensa del espacio privado son de vital importancia para formar a las nuevas generaciones que han de responder a las necesidades del nuevo régimen político. Se convierte en un rasgo distintivo de las dictaduras: "Las dictaduras siempre dominan reforzando la generalización, utilizando a la mujer como trasmisora del discurso patriarcal para que actuando desde la familia reafirme la estabilidad de la nación, de ahí que se convierta en objetivo de legisladores, moralistas, medios de comunicación y educadoras" (Campos y González, 1996). Algunos estudios han puesto de manifiesto las similitudes que se producen entre la doctrina falangista y la italiana fascista o incluso la nazi, "que se concretan en un antifeminismo abierto, que entroncaba en los países latinos con la misoginia católica y que se traducía en una exaltación de la maternidad y un interés en el aumento de la natalidad." 3

La Sección Femenina fue uno de los organismos que contribuyó a la formación del discurso ideológico de las mujeres españolas, reafirmando su posición de subordinación respecto al varón. Colaboró en la política educativa y natalista del régimen mediante la difusión de principios básicos de higiene y puericultura, junto con las orientaciones pedagógicas y enseñanzas femeninas necesarias para la formación de las futuras madres. Su labor formativa se divulgó a través de sus Escuelas de Hogar, cátedras ambulantes, etc. También organizó dicha institución el Servicio Social obligatorio para las mujeres, que consistía en cursos de formación sobre aspectos relacionados con la maternidad, y la enseñanza de las asignaturas de Hogar y Puericultura, obligatorias desde 1941 para las chicas en el Bachillerato. (Mira y Moreno, 2004, p. 326).

Las escuelas del franquismo eran escuelas segregadas porque la educación mixta en régimen de coeducación estaba prohibida por considerarse inmoral. La educación de las niñas se dirigía a formar "mujeres" y a prepararse para la maternidad. El currículo que se articuló respondía a una profesional del hogar y de la familia. De ese modo, en la Ley de enseñanza primaria de 1945 se dispone instruir a la mujer en disciplinas que contribuyeran a mejorar su vida en el hogar e iniciarlas profesionalmente en actividades relacionadas con ella: artesanía, industria doméstica, etc. Entre las disciplinas de 
orientación profesional que se recomiendan para la mujer se encontrarán profesiones afines con esta directriz: enseñanzas del hogar, labores, economía doméstica, cocina, puericultura, avicultura, cunicultura, sericultura, jardinería, enfermera, doncella, costurera, modista, bordadora, etc. ${ }^{4}$

\section{Perspectivas de cambio socio-educativo desde los años 50 hasta el inicio de la transición democrática}

En la década de 1950 comenzó una evolución imparable que se prolongaría e intensificaría a lo largo de los años sesenta. El régimen había evolucionado, entre otras razones por su apertura hacia el exterior, concretamente en lo que se refiere a relaciones internacionales. No obstante, continuaba siendo un régimen autoritario y de poder personal que se autodefinía como una monarquía católica, social y representativa. También la Falange perdería su categoría de partido único, por una comunión de principios, integradora de la pluralidad del régimen (Jover; Gómez-Ferrer y Fusi, 2001, pp.738-742).

El modelo económico que había imperado en España durante todo el primer franquismo, el autárquico (el de autosuficiencia económica y cierre de puertas hacia el resto del mundo, acabaría siendo insuficiente), provocó un descontento social que tuvo graves consecuencias. La rebelión de los estudiantes de Madrid, la independencia que Francia otorgó al Marruecos español, así como la crisis económica que se fue produciendo desde principios de 1956, fueron algunos de los acontecimientos que marcaron el devenir de la España de Franco. Como consecuencia se produjo una brecha entre las nuevas generaciones y el régimen, el fin de las esperanzas imperiales colonialistas y el fracaso del modelo político e ideológico del franquismo (Ibidem, p. 741). Todo ello llevó a los primeros atisbos visibles de movilización cultural en contra del régimen.

Con respecto a la Iglesia, el otro gran aliado del régimen, perdería parte de su poder. Protagonizó a finales de los años 60 y durante los años 70 algunos enfrentamientos con el Estado, como la desaprobación del episcopado, en 1970, de la Ley sindical por no responder a las exigencias de la doctrina social católica. Los sectores más progresistas de la Iglesia estuvieron en contra de la política del Estado, apostando y defendiendo la libertad de expresión, el derecho de huelga, el uso de las lenguas vernáculas, etc. Sin embargo, la Iglesia seguiría manteniendo importantes posiciones gracias al Concordato de 1953.5

A partir de finales de los años cincuenta, concretamente en el periodo que va de 1957 a 1975, España cambiaría gracias a un nuevo sistema político denominado "tecnopragmatismo" socio-político y económico (Ramírez, 1978, pp. 49-55). Estuvo protagonizado por las incorporaciones ministeriales de importantes tecnócratas del Opus Dei -López Rodó, Alberto Ullastres, Mariano Navarro Rubio-. Éstos promovieron la eliminación de los ideales económicos de la Falange y una liberación neocapitalista de la economía española, suponiendo una verdadera revolución enfocada a hacer de España un país industrial y urbano. España pasó a ser un país semiindustrializado, con la consiguiente emigración de las zonas rurales hacia las zonas 
urbanas, provocando un aumento de las clases medias y un crecimiento de las clases obreras vinculadas a la industria.

En este ambiente socio-económico, el tipo de familia española evolucionó de la familia rural en la que predominaban valores como la autoridad, la jerarquía y el trabajo familiar, a una familia urbana en la que empezaban a aparecer algunos atisbos que intentaban suavizar su carácter patriarcal (Carreño, 2002, p. 89-90). No obstante, la vida de las mujeres siguió sometida al silencio y a la clandestinidad, aunque "se conjugaron diversos factores para volver a dar a muchas mujeres españolas la conciencia de su opresión social y política: la oposición constante y multiforme al franquismo, las huelgas de finales de los años cincuenta, la crisis económica que obligó a las mujeres a volver a trabajar o bien a emigrar (1960-1964), el turismo extranjero, portador de otros modos de pensamiento y de vida” (Bussy, 2000, pp. 93-96). En algunos momentos, la prensa del régimen reconocía con entusiasmo y esperanza esa evolución en lo que respecta a la mujer: "La mujer española se ha lanzado a la calle como lo han hecho con anterioridad las americanas y las europeas del Norte [...] Las hijas de familias españolas de 1960 tienen otra mentalidad, otro concepto de la vida que sus madres y sus abuelas, y su campo de actividad se ha ampliado enormemente" (Hernando, 1960, pp. 93-96). Aunque, como expondremos más adelante, sólo conformaría una parte de la realidad femenina.

El surgimiento de una clase social nueva, provocaría una necesaria planificación educativa que respondiera a las nuevas demandas que se habían producido. La pérdida de poder y control de la Iglesia también afectaría a la enseñanza, la educación tenía un sentido más técnico y moderno.

A pesar de que vuelve a replantearse la cuestión de género en la enseñanza básica, la propia formación del integrismo católico continuó modulando las mentalidades y la sensibilidad de la mayor parte de las maestras. Para esta generación de maestras su dedicación a la enseñanza infantil aparecía vinculada a una cierta idealización de la vocación y al sacrificio (San Román, 2002, pp. 218-219). A ello debemos unir que el nuevo plan de estudios de las Escuelas Normales de 1967, seguía diseñando actividades diferentes para alumnos y alumnas en la asignatura de "Didáctica de la Formación del Espíritu Nacional”, así como la asignación de asignaturas destinadas exclusivamente para las alumnas como, por ejemplo, la Manualización del Hogar. De esta manera, durante todo el periodo franquista se produjo una clara diferenciación del currículo por cuestión de género. Esto, a su vez, exigía una formulación explícita de contenidos, prácticas y espacios que desarrollaran esa feminización de la enseñanza legitimando así la identidad femenina (Núñez y Rebollo, 2003 p. 232). Ello se vio respaldado por las mujeres que desde el ámbito político -como la Sección Femenina-, y desde el ámbito religioso -a través de Acción Católica- venían defendiendo y formando a las nuevas generaciones femeninas en los ideales del régimen desde el triunfo de Franco.

\section{Mujeres educadas para la maternidad y relegadas al espacio privado del hogar}

Los discursos educativos de las mujeres a cargo de la Sección Femenina se propagaron a lo largo de todo el franquismo por distintas vías de comunicación y acciones educativas, 
siendo la publicación periódica "Consigna” una de las representaciones ideológicas que tuvo dicho organismo durante casi 40 años de vigencia, desde 1940 hasta $1977^{6}$. Es una revista profesional dirigida, en un principio, a maestras falangistas, aunque se fue extendiendo a todo el magisterio, de forma especial, a las maestras, a las maestras rurales y también a las mujeres en general. Esta publicación sufre diversas modificaciones en la denominación del público al que se dirige (maestras, profesorado...) en consonancia con la terminología del contexto socio-político en el que se desenvuelve. Las diferentes secciones también cambian a lo largo de todos estos años, sobre todo en las dos últimas décadas de los años 60 y 70. Los capítulos destinados a la formación religiosa y política se mantienen, aunque cobran mayor importancia los aspectos de interés más profesional para el profesorado. De todas las secciones, adquiere especial relevancia para nuestro estudio la parte destinada a las orientaciones pedagógicas dirigidas a las maestras, a las madres o a las futuras madres, debido a los modelos educativos que la Sección Femenina quiso transmitir en esta publicación, así como los artículos de opinión donde las mujeres comienzan a recuperar el protagonismo en el espacio público en cuanto a su finalidad, función, participación, etc.

En una primera etapa de la revista, las orientaciones pedagógicas correrán a cargo de Francisca Bohigas -en la mayoría de las ocasiones-, desde 1940 hasta 1954. El contenido, que se desprende de estos primeros quince años, se orienta hacia tres niveles de actuación: la pedagogía familiar o escuela de padres, las orientaciones pedagógicas dirigidas a las cuestiones educativas originadas en la escuela y la orientación profesional femenina ${ }^{7}$. A partir de 1954 se produce un cambio en la denominación del apartado -recibió el nombre de sección pedagógica-, así como la autoría de dicho capítulo, que a partir de ese momento correrá a cargo de un hombre, Francisco Secadas y de otras personas procedentes de diversos ámbitos: médicos, publicistas, profesores, etc. Los motivos de este cambio obedecen más a la inclusión de diversas temáticas educativas relacionadas con las necesidades educativas del magisterio en general y el asesoramiento o formación permanente que estaba demandando el profesorado. Observamos ciertos cambios en cuanto al estilo de redacción, se utiliza el masculino de forma genérica, y los temas que se tratan, en una gran mayoría, son textos entresacados de manuales o libros de pedagogía. De algún modo, se introduce una mayor profesionalización o especialización de determinadas cuestiones educativas. No vamos a detenernos en el análisis pormenorizado de esta sección, sino que intentaremos extrapolar desde una perspectiva global los principales mensajes o modelos educativos que se desprenden en esta revista.

El propósito o finalidad que pretendía la Sección Femenina con motivo de la publicación de la revista Consigna era doble, según queda recogido en su primer número: por un lado, servirá de acción educadora de la mujer y, por otro lado, servirá de vehículo trasmisor o de comunicación con las maestras afiliadas para orientarlas en su labor docente, pero no sólo a las maestras, sino que también se hace extensiva dicha orientación a las madres: "Y en la esfera del hacer escolar y familiar, procuraremos que la Madre y la Maestra, con su acción individual, además de seguir las doctrinas de la Iglesia y las leyes del Estado, con tacto y prudencia, cooperen a la coordinación social de la acción 
educadora de la Iglesia, la familia, la Escuela y el Partido, único modo de que llegue a ser una, en su complejidad y variedad, la educación del niño." (1940, no 1, p. 15).

Respecto a los valores o contenidos educativos que se deben tener en cuenta para formar a las nuevas generaciones, se recomienda acudir a los 26 puntos de Falange Española y a la Encíclica de Pío XI acerca de la educación cristiana y de la juventud: "La Carta Encíclica de Pío XI sobre "Educación cristiana de la juventud", en la que se afirma que la educación es obra necesariamente social, no solitaria. Ahora bien, tres son las sociedades necesarias, distintas, pero armoniosamente unidas por Dios, en el seno de las cuales nace el hombre: dos sociedades de orden natural, tales son la familia y la sociedad civil; la tercera, la Iglesia, de orden sobrenatural." $\left(1941, n^{\circ} 4\right.$, p. 11). Las atribuciones educativas relativas a estas tres instituciones son argumentadas por la revista dos años más tarde:

"la educación corresponde a la familia por naturaleza, y no es solamente un derecho, sino una obligación, de cuyo cumplimiento habrán de dar los padres, cuenta a Dios [...] A la Iglesia corresponde también la educación de la infancia por su maternidad espiritual y tiene derecho a la educación religiosa-moral de sus miembros [...] La educación también corresponde al Estado en orden al bien común. Y en la actualidad, el Estado ha concedido a la Sección Femenina de F.E.T. y de las J.O.N.S. y al Frente de Juventudes determinadas funciones educativas para complementar la acción educadora de la familia y de las instituciones que el Estado sostienen para tal fin". (1943, nº 34, pp. 20-21)

Desde esta tribuna mensual, la Sección Femenina, abanderada por Pilar Primo de Rivera, presenta el nuevo modelo educativo y las nuevas directrices dirigidas a las mujeres (madres y maestras) que se extenderán en todas direcciones. Había que crear una nueva sociedad construída con los valores del nuevo régimen basados en el nacionalcatolicismo. En un primer momento, las maestras serán las encargadas de enseñar los valores falangistas dirigidos a las niñas: "Y os exigimos a vosotras, camaradas Maestras, una moralidad perfecta, una formación religiosa a fondo y un espíritu NacionalSindicalista que provenga de que en todo vuestro ser sois falangistas. Pero no creáis que os queremos ñoñas ni tristes; junto con esta formación fundamental de que os he hablado tenéis que poner vuestro espíritu a la altura de los niños" (1940, nº 1, p. 2).

La figura de la maestra es potencialmente muy fuerte, a ella se la encomienda la formación del resto de mujeres. El contexto rural se consideró como el más virgen y puro. De este modo, adquiere especial importancia la maestra rural como motor regenerador de la sociedad rural. Tanta importancia se concedió a la vida rural que la Sección Femenina, por medio de la Hermandad de la Ciudad y el Campo, puso en marcha la organización de las Granjas Escuelas de Orientación rural de la mujer, de carácter local: "Hay que elevar a todo trance el nivel de la vida en el campo, pero como el espíritu necesita como base y cimiento de la materia, a ésta hemos de atender en primer lugar, si no queremos, que el edificio de la grandeza de la Patria, falto de sustentación, se venga abajo." (1941, nº 2, p. 26). 
Estas orientaciones se circunscriben a los principios del nacional-catolicismo imperantes en los primeros años del franquismo. Resulta interesante destacar que en este primer periodo adquieren mayor relevancia para la formación de las mujeres el trasfondo ideológico y político de la Falange y el sentido trascendental de la vida que tiene la religión católica. La Sección Femenina se convirtió en el organismo encargado de proporcionar la formación de la mujer en el ideario franquista, esto es la formación política de la mujer, la preparación para el hogar, la educación física y la formación musical en los distintos centros que creó para cada una de las especialidades ${ }^{8}$.

Desde estos planteamientos, la construcción del género en esta primera etapa del franquismo se plantea desde posiciones tradicionales en donde se perfila, de forma indisoluble e inseparable, la identidad de la mujer ligada a su papel en la familia: será la educadora de los hijos y la perfecta esposa relegada al hogar doméstico, a excepción de las dedicadas al magisterio, considerado como una profesión femenina continuadora del hogar.

Una de las principales metas o finalidades de la formación femenina, desarrollada por este organismo, es la preparación de la mujer para el hogar. "Y en ese camino se unifican la tradición con la tendencia del futuro; ayer y hoy para los españoles es fundamental la vida de familia; y es aspiración general preparar lo más adecuadamente posible a las adolescentes para la dirección del hogar." (1943, no 30, p. 31). Se llega a establecer una relación de dependencia entre la pedagogía y el hogar. "La Pedagogía servirá al hogar para ayudar a la familia a completar y perfeccionar la educación de la prole" (1943, no 31, p. 20). La misma relación se establece entre mujeres y maestras:

"Se llama a la madre con la misma razón que a la Maestra: y al Hogar y a la Escuela se encomienda la tarea de educar conjuntamente al hombre y a la mujer nuevos [...] La niña ha nacido para el hogar. Como educáis a futuras madres, no debemos perder de vista que toda nuestra acción escolar va encaminada a dotar a la niña de los recursos necesarios para gobernar, moral y económicamente, el hogar. La educación específica de la mujer para esposa, madre y educadora de los hijos, debe, iniciarse en la Escuela Primaria. Es preciso que vosotras, Maestras nacionales, estéis orientadas acerca de cómo puede gobernarse un hogar, para, así guiar a vuestras alumnas.” (1941, no 9, p. 10)

En este afán de vincular la pedagogía y el hogar, resultan interesantes los artículos que se dirigen a las madres y a las maestras. Se van infiltrando algunas orientaciones acerca de fomentar el sentimiento patriótico o conciencia nacional de servicio a la patria, así como el sentimiento religioso o educación religiosa que se debe inculcar desde el hogar?.

De forma paralela, se justifica la maternidad desde el punto de vista fisiológico, incorporando artículos procedentes de la medicina en los que la finalidad de la mujer se argumenta en función de su capacidad reproductora. Destacamos de forma especial el artículo de un célebre ginecólogo de la época -Dr. José Botella Llusía-, en el que señala los peligros de la civilización moderna para la biología de la mujer, y defiende que, como el fin de la mujer es la maternidad, a él se debe dar, evitando las modas 
introducidas por la mujeres modernas, como el alcohol, el tabaco, la esclavitud de la moda, la imitación del hombre debido al "falso concepto de inferioridad en que se ha tenido a la mujer durante siglos por parte de los hombres y por parte de las mujeres." $\left(1943, n^{\circ} 27\right.$, p. 44). Por ese motivo, defiende que la mujer sólo debe trabajar en casa y en el cuidado de los hijos, mostrándose en contra del trabajo de la mujer fuera de casa porque realizará un trabajo doble y la salud se resentirá. La mujer moderna, según el autor, necesita ser reconstruida con los planteamientos de la medicina y la biología. La argumentación de su finalidad se dirige hacia la defensa de permanecer relegada al espacio privado del hogar familiar: "que la mujer permanezca en su hogar, que no luche por la existencia, que su máxima aspiración sea pensar en casarse y después en cuidar a su marido y a sus hijos. Que ni de soltera ni de casada se salga nunca del círculo de la familia." (p. 47). Incluso, aunque se le enseñe a la mujer un oficio o se le proporcionen estudios para desempeñar un empleo o trabajo en el espacio público, su finalidad es perfeccionar a la mujer en su misión de compañera y de madre, o para que puedan solventar las mujeres solteras la falta de hombres en su hogar. Esto no significa que se reclame una equiparación de la mujer al mismo nivel que al hombre, sino que le proporcione una mayor libertad e independencia (1943, no 33 , p. 34).

La función biológica de la mujer es planteada como una tarea irrenunciable, ser madre y esposa, aunque ha de ir acompañada del fin sobrenatural y moral para el que se deben formar hombres y mujeres. El sentido trascendental estará presente a lo largo de todo el discurso educativo de la Sección Femenina, así como el desarrollo de una conciencia nacional patriótica y española ${ }^{10}$. La formación de las mujeres, por tanto, estará muy vinculada a los fines y funciones que se les otorga: "crear hijos, educar, administrar un hogar y crear valores morales [...] el verdadero contenido de la educación femenina habrá de abarcar los fines y obligaciones que la mujer habrá de cumplir durante su vida [...] La mujer, que tanto influye en la formación de sus hijos, debe tener también ideas claras y concisas en su expresión, acerca de cuanto se relacione con la defensa de la Patria [...] ha de responder a cuanto pida una familia cristiana y española." (1943, no 29, pp. 21-23).

La educación de las mujeres tenía como objetivo responder a la función social que se asigna a este género. De esa forma, el currículo se circunscribe al ámbito del hogar y los deberes que de él se derivan, respondiendo al modelo ejemplar femenino predominante en este periodo. La instrucción femenina debe estar relacionada con el hogar, el cuidado de la familia y de los hijos. Todo ello acompañado de una conciencia nacional (patriotismo) y de una instrucción religiosa basada en las Encíclicas ${ }^{10}$. En palabras de Pilar Ballarín expresamos lo que supuso esta nueva orientación para la mujer: "Catolicismo y patriotismo se unirían así en un todo indisoluble. Al silencio, modestia, obediencia y subordinación católicas tradicionales, las nuevas mujeres debían añadir los componentes propios de los regímenes totalitarios de la época: la heroicidad del día a día y un nuevo sentido de la feminidad donde la suavidad, dulzura, abnegación y sentido de la belleza reinarían en el interior del hogar" (Ballarín, 2001, p. 114).

Por otro lado, la identificación entre mujer y familia se hace cada vez más patente en esta publicación. Se aprecia una relación estrecha entre la familia (madre) y la escuela (maestra), este binomio vincula la finalidad de las mujeres en una misma dirección, 
puesto que la madre junto con la maestra serán las educadoras de la nueva sociedad. La familia se convertirá en la primera escuela para el niño o la niña, en la primera institución educadora, como ya se ha recogido más arriba. De este modo, la defensa de la familia se legitima en un modelo patriarcal de la misma, por ello la política franquista incorporó disposiciones legislativas que dificultaron la incorporación al mundo laboral de la mujer casada con el objeto de que se dedicara en exclusividad a su papel de esposa y madre. ${ }^{12}$

\section{Mujeres perfectas, mujeres "totales"}

A partir de los años cincuenta la revista Consigna refleja una ruptura, aunque relativa y limitada, con respecto al modelo de mujer del primer franquismo en el que imperó el adoctrinamiento político y religioso basado en los principios ideológicos del Movimiento Nacional. En estos momentos, aparece una imagen de mujer en la que perduran los elementos básicos que configuran el modelo tradicional femenino imperante en aquellos tiempos, pero con una carga ideológica y política menos visible. Las mujeres siguen siendo definidas por su altísima misión como reinas del hogar, como formadoras de sus hijos y, en un nivel superior, como las educadoras de la futura sociedad. Todavía en 1959 son conceptuadas como "educadoras originales designadas por Dios" y la maternidad se representa como "la vida ordinaria para alcanzar su propia perfección" (no 223, p. 31).

No obstante, la sociedad española empezaba a cambiar el enfoque sobre la situación de las mujeres frente al trabajo, la educación y la familia. Aunque, muchos de estos avances fueron asumidos desde una visión rotundista y problemática. La incorporación de las mujeres a la esfera pública, concretamente al mundo laboral, se veía con cierto recelo todavía y como un mal inevitable. Frases como éstas lo atestiguan: "No sabemos si a fuerza de machacar o porque lo inevitable, aunque sea un mal, se impone a las circunstancias, lo cierto es que en todo el mundo se va teniendo muy en cuenta la actividad profesional femenina" (1959, no 219, p. 50), o esta otra: "La mujer, que cumple su misión en estas tareas un poco a "contra pelo", se está ganando ese respeto hasta de los más reacios, que ya admiten, aunque con ciertas reservas, su colaboración. La salida de las mujeres fuera de su hogar, es considerado como un fenómeno social del siglo, necesario e irreprimible por muy antinatural que parezca” (1958, no 208, p. 41).

En el origen de esa visión ambigua aparecían dos cuestiones claves. Por un lado, si este cambio iba a provocar el abandono de la misión primordial para la que fue creada por Dios, la maternidad. Y, por otro lado, y en consecuencia, cómo debía focalizarse la educación de las mujeres ante tal situación, sin que se perdieran sus dos cualidades básicas: la catolicidad y su feminidad. Se partía de la idea de que estas dos características típicamente femeninas eran clave para conjugar su labor profesional y su alta misión como mujer.

Las profesiones a las que podían aspirar debían encuadrarse dentro de las aptitudes femeninas: maestras, profesiones sociales, enfermeras, farmacéuticas, actividades relacionadas con el hogar, etc. Se reconocía que la orientación profesional de las jóvenes debía salvar los inconvenientes de orden psicológico y social existentes en la sociedad. 
Pero, al mismo tiempo, se aludía a un criterio prioritario para decidir las más idóneas, basado en las condiciones físicas y psicológicas de las mujeres, sin olvidar la misión social que se les había confiado (1953, no 148, p. 34). "La profesión femenina debe aproximarse a la vida de la familia; a la esencia misma de la mujer, pertenece ser siempre y en todas partes madre, entregarse y sacrificarse, cuidar con solicitud determinadas personas" (1959, no 219, p. 21).

Como se puede comprobar, durante esta etapa se siguieron vinculando y proyectando aquellas capacidades y aptitudes que las mujeres venían desarrollando en la esfera privada, es decir en el hogar, con las que podían desarrollar y poner en práctica en la esfera pública en el ejercicio de una profesión. Incluso las cualidades femeninas aparecían como antónimos de las de los hombres, y se enfrentaba la intuición femenina, al razonar "lógico" masculino, así como la "unidad" de la mujer, frente a la "dualidad" del hombre (Ibidem).

$\mathrm{Al}$ mismo tiempo, numerosos testimonios de la época reflejaban que la mentalidad femenina empezaba a vislumbrar tímidos cambios, determinando cierta ruptura con el periodo franquista anterior. Entre éstos, se criticaba el trato discriminatorio y el tópico sobre la incapacidad biológica y psicológica que los varones venían prodigando sobre ellas, así como la ausencia de una verdadera aprobación de aquellas que habían decidido dedicarse a ser "embajadoras, deportistas, políticos [sic] o escritoras", enjuiciadas con "cierta guasa y frivolidad" (1957, no 192, p. 29) que las ridiculizaba. Frente a esta situación, las propias mujeres destacaban su capacidad del deber y de la responsabilidad que las hacían aptas para ocupar puestos de trabajo relacionados con el desempeño de funciones públicas, incluso de carácter directivo. La denuncia también llegaba a la injusta situación de la mujer formada, la mujer universitaria, preparada y profesional, que vivía en un escenario de inferioridad respecto al hombre debía ejercer la profesión para la que se había preparado, como ocurría en el ámbito académico en la ocupación de las cátedras de Universidad (Familia Española, 1961, no 16, p. 67; Consigna, 1958, no 206, p. 47).

Por otro lado, la apertura hacia Europa empezaba a tener cierto calado en la prensa oficial del régimen. Se destacaban las conquistas de mujeres europeas. Por ejemplo, de las francesas, se exponía cómo de 1900 a 1940 pasaron de ser 900.000 a 6.000 .000 las que trabajaban en toda clase de profesiones. $\mathrm{O}$ de las italianas, su incorporación a un sector profesional impensable anteriormente, como el cuerpo de Policía Femenino de Italia (1959, no 220-221, p. 34-36). Se aludía también a datos estadísticos en lo que respecta a la población activa en distintos países en comparación con la situación española -concretamente a que el 16\% de la población activa en España era femenino, frente al 35\% de Francia, el 36\% de Alemania Occidental, el 25\% de Italia, el 31\% de Inglaterra o el 27\% de los EE.UU. (1964, no 54, 94)-.

Esta crítica no sólo abarcaba al sector varonil de la población, también se hizo extensible a las propias mujeres de las clases altas, que aunque recibían educación, dedicaban "su vida exclusivamente a lucir en salones, cenas y lugares de moda". Asimismo, ensalzaban a aquellas mujeres de la misma clase social que sentían "el deseo de ser algo más que objetos de adorno y frivolidad y que buscan ocupaciones más 
satisfactorias" (1960, no 3, p. 94). A pesar de mostrar cierto avance, este nuevo modelo de mujer que empezaba a construirse, permanecía sumergido en un sin fin de restricciones sociales y morales.

En lo que respecta a la educación, los datos eran reveladores. En 1955, el 42\% del alumnado en centros de enseñanza primaria, secundaria y superior eran mujeres. Especialmente, la cifra de alumnas matriculadas en la Enseñanza media presentaba cambios significativos. A pesar de estos cambios potencialmente positivos para las mujeres, éstas tuvieron que enfrentarse a un discurso ambivalente y contradictorio. Por un lado, empezaba a ser bien valorado que las mujeres recibieran educación, formación, que ejercieran una profesión con la que ayudarían al desarrollo y porvenir de la patria ${ }^{13}$ (Pérez, 1960, p.51), así como su incorporación al mundo político. Incluso empezaban a surgir planteamientos teóricos que trataban de esbozar y analizar una psicología diferencial entre hombres y mujeres desde un enfoque menos discriminatorio para éstas (1959, no 222, pp. 13-16). Pero, por otro lado, aquellas mujeres que trataron de beneficiarse de estos avances, eran calificadas de pretenciosas y soberbias ${ }^{14}$. Y es que en el fondo, continuaba presente ese discurso tan tradicional sobre la posición social de las mujeres en el escenario público, y de éstas con respecto a la de los hombres. En el mundo laboral, su función perduraba como meramente complementaria y nunca sustitutoria de los experimentados varones: "la actividad extrahogareña de las jóvenes de España no significa movimiento de lucha contra el varón, sino complemento y ayuda. Es, sencillamente la aceptación de responsabilidades, la comprensión de que la vida es quehacer y obligación que hay que cumplir” (1960, no 3, p. 94). Además se añadía que "las mujeres españolas que trabajan y estudian siguen soñando con casarse y tener muchos niños y no creo que ni la universidad, ni la oficina, ni el taller impidan ser buenas hijas ni buenas hermanas" (Ibidem). Esto significa que seguían siendo definidas por su misión como futuras mujeres dependientes y sometidas al modelo de "ángel del hogar", en el que debían imperar sus capacidades sensitivas, de sufrimiento, de abnegación, su virtud y su profunda fe (1962, no 37, pp. 69-70). Un calco perfecto del modelo de mujer que se impuso en el primer franquismo.

El hogar era su verdadero campo de acción, y la familia la primera en beneficiarse de la formación que éstas habían recibido. De esta forma, su educación, cultivo y formación quedaban limitados al verse proyectados en la familia. Esta situación llegaba hasta tal punto, que más que contribuir a su propio beneficio con la pretensión de favorecer su independencia y su proyección personal, la mujer más valorada era aquella que permanecía en el anonimato y anulaba su talento en aprovechamiento de los demás -del varón-. Todavía en 1957 la revista Consigna publicitaba un "modelo de mujer decorativa" (1957, no 267, p. 1) ${ }^{15}$, apoyándose en la idea que ésta seguía siendo el sexo débil $^{16}$. Con todo esto, se estaba demandando que las mujeres no sólo perdieran su independencia, sino también su identidad:

"a veces puede resultar más fecundo, más maravillosamente fecundo y valioso, el viejo y difícil camino trillado por tantas mujeres que nos precedieron: el de perderse a sí mismas en el anonimato de la tarea menuda de acompañar a otro. Debe olvidarse voluntariamente de uno mismo, para exaltar al otro. De enterrar 
su propio talento [...] para que sirva de abono al talento del otro. De fundir sus propios gustos en los gustos ajenos" (no 189, pp. 37-38).

Por tanto, a pesar de querer demostrar por una parte, ese cambio de mentalidad respecto a las posibilidades de emancipación de las mujeres, por otro lado, se trató de convencer a todas aquellas mujeres incorporadas a la vida pública y laboral de que debían seguir manteniendo entre sus principios los mismos ideales cristianos que sus antepasadas. La familia seguía conservando el tono más tradicional (1958, no 208, pp. 41-43), siendo la piedra base y angular de la sociedad española. Se aspiraba a que las féminas fueran en un futuro "mujeres completas". Entre otras orientaciones se afirmaba que:

"Desde niña la mujer es femenina, y su diferenciación del niño se manifiesta hasta en los detalles más pequeños y en los más pequeños juegos. El cuidado puesto en su educación se reflejará más tarde en el hogar, donde la niña, ya mujer, tiene que formar a todos lo que la rodean: marido, hijos [...] ¿qué hace una mujer que sólo sabe coser y fregar? ¿O una que sólo sabe hacer cuentas? ¿O una que sólo aprendió a presumir totalmente por paseos y fiestas? Porque tan incompleta anda la una como la otra. ¿̨Y no es una grave responsabilidad de una Maestra, o de una educación, el no haber hecho fructificar por completo la semilla sembrada? [...] Si ponemos a nuestras mujeres en posición de ser mujeres totales, habremos hecho desaparecer tantos hogares desgraciados e incómodos que hoy aparecen en nuestra sociedad. Porque la madre mujer hará a sus niñas como nosotros la hicimos a ella [...] Es un llamamiento a la conciencia y a la responsabilidad de cada Maestra" (no 208, 1958, 30-32).

Para poder desarrollar este modelo femenino de educación "total" se partía de unas concepciones teóricas básicas sobre la mujer. A pesar de ser considerada "un alma capaz de salvarse o conducirse, un ser político social, un cuerpo físico compuesto de células y órganos delicados, un ser femenino y un ser social", había cierta preocupación sobre las posibles diferencias psicopedagógicas entre niños y niñas. Se planteaba la antinomia herencia-ambiente que les llevaba a preguntarse: “¿Son las niñas así por naturaleza o es el molde educativo en que están metidas desde que nacen lo que las ofrece al juicio de los educadores como mejor dotadas? La educación de las niñas se hace machaconamente sobre la atención, orden, limpieza, corrección. Cuando alguna niña no acepta, se la denomina despectivamente ¡muchachote! Se fomenta en ellas más el parecer que el ser. No es raro que puntúen bajo en lealtad, franqueza, camaradería: influjo del medio y no bueno en este caso" (1959, no 224, pp.11-14). Como se puede observar, se estaba ofreciendo una visión más innovadora sobre la psicología infantil. Pero, el modelo social enraizado en la sociedad española en décadas anteriores, seguía imperando, lo que implicaba una educación para niñas basada fundamentalmente en una educación religiosa -haciéndola vivir una vida cristiana completa-, educación política -que la integre en el momento presente de la Historia-, educación física-capaz de darle el pleno desarrollo de los elementos que componen su fisiología-, educación intelectual, estética y social -que permita su integración dentro del ambiente de su 
vocación-, incluso una educación sexual -de modo que no se despierte la curiosidad malsana hacia los secretos de la vida- (1958, no 208, pp. 30-32).

La preparación para el hogar seguía siendo una asignatura de gran importancia. Pero, a diferencia de la etapa anterior, el objetivo era intentar darle un sentido más profesional. Se toman como ejemplo los países de Francia e Inglaterra. En ellos se celebraban todos los años concursos para premiar al Hada del Hogar, es decir, para premiar a la mujer que más arte se daba en organizar las faenas domésticas. Esto se consideraba de una gran trascendencia social, ya que revalorizaba a la mujer como reina del hogar. Si la mujer era aglutinante de la familia, "cuanto más atractivo haga el hogar, y sin descuidar los aspectos prácticos de la vida, hace de él un rincón ideal y realiza una importantísima tarea social”. Así la mujer, sin salirse de su puesto, tenía una gran tarea social (1959, no 218, pp. 43-45).

La maestra, como receptora de todas estas consignas, era responsable directa de que las niñas, futuras mujeres, aprendieran estas lecciones, entre las que se encontraba la formación familiar y social (1956, no 182, pp. 67-70). Esta pedagogía familiar implicaba la identificación de las maestras con las educadoras familiares de la sociedad, que junto a las madres, prepararían para la maternidad a las niñas bajo el lema: "se puede preparar para ser buenas madres a las que son niñas todavía” (1959, no 225, pp. 7-11). También se utilizaron mensajes como éste: "Porque tú has de dar fruto. Todas las niñas lo piensan muchas veces: un día ellas, como sus madres, llegarán a tener hijos, cuidarán del marido, de la casa, de los muebles, de los bienes del hogar. Un hijo. Ese es el fruto que llevan en potencia tus deseos de mujer" (1956, no 183, pp. 63-65).

Para completar la formación de las niñas se continuó con una labor de formación política acorde con los postulados del Estado. Las campañas de las Juventudes de Sección Femenina emplearon sus esfuerzos en adoctrinar las mentes infantiles, utilizando como principal instrumento a la maestra. A ella le correspondía influir en las niñas para que éstas se afiliasen. Para conseguirlo, utilizaron una estrategia basada en contraponer el bien y el mal. Enfrentaban a aquellas niñas afiliadas a las que se les asignaban cualidades bien valoradas socialmente, como el ser "generosas, alegres, valientes, decididas", frente a otras niñas que no estaban afiliadas y que eran calificadas como "envidiosa, perezosa, poco clara y que siempre hace las cosas a regañadientes" (1956, no 182, pp. 63-65). Todas debían aspirar a ser como Santa Teresa de Jesús. Ésta fue uno de los modelos de mujer idealizados de forma más sobresaliente durante la primera etapa franquista. De ella se destacaba el "correr ella sola, todos los caminos de España para abrir nuevos conventos de carmelitas que dieron más gloria a Dios, y tan natural y sencilla que no le intimidaba hablar con el rey cuando tenía que hacerlo y ni le importaba cocinar para sus monjas aun siendo ella la superiora” (Ibidem, p. 63).

\section{La participación de las mujeres en el espacio público}

A partir de los años sesenta las posiciones sociales corroboraban una proyección social más avanzada sobre las mujeres. Precisamente por ello, la imagen de esta mujer "moderna" y de la familia estaban en crisis. Ello fue debido a las nuevas exigencias culturales, económicas, políticas, ecológicas, y también a una mejora en el grado de cultura de las mujeres, del puesto social que ocupaban, y a su propia experiencia 
(Familia Española, 1965, no 64, 11-16). Todo esto fue determinante para que se produjeran cambios en las estructuras sociales. Esa evolución era percibida por una parte de la sociedad como algo irreversible, muy a pesar de los sectores más reacios. La Ley de Derechos Políticos, Profesionales y de Trabajo de la Mujer de 1961, contribuiría con este imparable cambio. De nuevo, se utilizaron como ejemplo la situación social y laboral de otras mujeres europeas (1965, no 70, pp. 25-29 y 74-78). También se expusieron públicamente las concepciones críticas de las mujeres sobre los hombres -entre las que se encontraban el rechazo a ser interpretadas vulgarmente por los hombres, a no reconocer a aquellas mujeres capaces de competir intelectual o económicamente con ellos sin que perdieran su feminidad, etc. (1962, no 68, pp. 4347)-. Todos estos acontecimientos empezaban a vislumbrar esperanzas de cambio para las mujeres españolas de esta época.

La familia ya no aparece vinculada en exclusividad a la figura de la mujer. Por el contrario, es entendida como una "empresa educativa en la que los padres naturalmente, ejercen la dirección". Ahora, se desterraba el modelo autoritario por un modelo en el que la familia "educa, orienta en unas verdaderas concepciones de la vida, transmite unas tradiciones, fomenta y encauza hábitos positivos y propone a sus miembros jóvenes unos objetivos para la vida profesional y social". Y lejos de esa tradicional rigidez familiar imperante en España, esta nueva familia debía crear y aportar además, "un ambiente de estímulo o de apoyo, que se instrumenta de un modo informal, según las características de cada familia concreta, gracias a unos ingredientes básicos de los que varía la calidad e intensidades: elementos culturales, elementos efectivos, elementos morales..." (Consigna, 1962, no 258, p. 21-26).

La incorporación de las mujeres al mundo laboral aparece más asumida que en la década anterior. "La mujer ha superado ya aquella situación que la limitaba a un dulce papel decorativo, aunque éste estuviera lleno de sentido y dignidad en algunos casos. Antes el caso de las mujeres escritoras como el de la mujer pintora, era muchas veces la excepción [...] Hoy, afortunadamente, es ya un suceso natural, y las mujeres acuden con su obra, en igualdad de circunstancias, sin causar asombro, a los concursos literarios o artísticos" (1960, no 267, p. 1). Incluso se justifica positivamente que los hijos no sean entregados en exclusividad a las madres. Las guarderías son reconocidas como espacios subsidiarios de las familias donde se favorece tempranamente la convivencia entre los niños (1962, no 258, p. 21-26). No obstante, todavía las mujeres más avanzadas de esta época denunciaban que la participación activa de las españolas seguía siendo deficitaria. Continuaban apareciendo opiniones femeninas en las que se asumía la debilidad natural de las mujeres frente a los hombres ${ }^{17}$. Asimismo, la orientación profesional mantenía entre sus principios unos puntos básicos calificados como propios del desarrollo educativo femenino, como eran:

"1.Reformar la formación Humana de la niña para que como mujer no se le ponga en situación de que por la profesión se inhiba de su fin concreto en la vida.

2. Por la variedad de los procesos técnicos, se procurará darles una capacidad para el trabajo en sí. 
3. La variedad de los procesos técnicos debe basarse en orientar a la mujer hacia las profesiones más aptas para ella.

4. Se cuidará al hacer el montaje de las diversas técnicas de procurar que sean aquellas que tengan mayores posibilidades de encuadramiento en la comarca, provincia o región" (1965, no 292, 11-14).

A lo largo de la década de los sesenta y, sobre todo, de los setenta, la sociedad española experimentó múltiples transformaciones en la mentalidad colectiva y en los modos de representación, que condujeron a un cuestionamiento del discurso tradicional de la mujer, que coincidió con la transición a la democracia. Pese a estos avances, el discurso de la Sección Femenina no se transformó demasiado, tal y como señala la profesora Carmen Agulló: "la construcción del género femenino adopta una estética moderna pero su eje central es el niño” (1994, p. 501). En este periodo tecnócrata emerge un nuevo modelo que en palabras de esta autora se orienta hacia una mujer consumidora, que consume y produce, trabaja en casa o en profesiones femeninas, bajo el impulso de los nuevos planes de desarrollo industrial (2005, p. 28). Este modelo deja visible a una mujer que sigue dedicada al cuidado del marido y de los niños, aunque posee una mayor cultura y educación, así como un bienestar económico, como consecuencia de la introducción de los electrodomésticos en los hogares españoles. La tecnificación permitía compaginar las tareas del hogar con el ejercicio de una profesión. Pero las mujeres no debían olvidar que su función principal debía ser el hogar (Rabazas, 2001, p. 436).

La participación activa de las mujeres en el espacio público se hace visible en la revista Consigna a partir de la década de los setenta. En 1970 se publican las conclusiones del Congreso Internacional de la Mujer ${ }^{18}$, dedicado a La mujer en el mundo de hoy. En el Congreso se abordaron diversos aspectos en relación con la situación y responsabilidad familiar de la mujer, su condición laboral, su participación política, su acceso a la cultura, etc. De las conclusiones que se señalan, no quisiéramos pasar por alto la importancia que se concede al trabajo doméstico y la reivindicación de asignar un salario a dicha actividad (1970, no 346, p. 10). También se reclama la igualdad de trato educativo y de oportunidades para la mujer, lo que quizá podría interpretarse como un tímido avance a favor de la igualdad educativa del género.

El protagonismo político de la Sección Femenina aumentó en los años de la transición política. Este organismo asumió las tareas de coordinación y representación de un sector de población femenina afín al régimen político que comenzaba a eclipsarse. ${ }^{19}$ De la misma forma que se reivindica desde otros foros feministas un mayor protagonismo de la mujer en la sociedad española, este organismo también reclama una mayor presencia política de las mujeres, proponiendo actuaciones que permitieran: "hacerla electora, colaboradora, público responsable y no masa anodina y fácilmente impresionable. La mujer, en esta hora de nuestro tiempo, en este 1974, ha de abordar con urgencia estas tareas de promoción y participación política. Ha de intensificarse su presencia y su papel de protagonismo en los colegios profesionales, en el mundo laboral y, sobre todo, en el ámbito de la acción sindical” (1974, no 394, pp. 29-30). 
Con motivo del Año Internacional de la Mujer, declarado por la ONU en 1975, la Sección Femenina publicó diversos artículos en torno a la función de la mujer, figuras de mujer, situación laboral, medidas legislativas respecto a la mujer trabajadora, etc. El protagonismo de la mujer se hace cada vez más notorio en la sociedad española por medio de la participación en foros, congresos, asambleas, asociaciones, etc. ${ }^{20}$ No obstante, desde la revista Consigna se plantea la participación de la mujer en colaboración con el hombre, no como rival, para distanciarse de las propuestas de los movimientos feministas que demandaban un cambio radical en la situación de la mujer, desde diferentes posiciones ${ }^{21}$ : "El movimiento de mujeres cuestionaba el patriarcado y principios vinculados al mismo como la familia o el mito de la maternidad. Pero mientras que las marxistas se limitaban a un rechazo de la maternidad como destino y a un interés por la anticoncepción y el aborto, las feministas radicales insistían en la exploración de la sexualidad como relación de placer y no de dominación" (Mira; Moreno, 2004, p. 330).

Desde una perspectiva crítica, se rechaza la imagen de ciertas mujeres que salen al espacio público: "La mujer de hoy por desgracia, ha hecho su irrupción descarada en el mundo del erotismo suelto, de la exhibición pornográfica, de lo excesos verbales, de las extravagancias hippies, de la renuncia a la feminidad, de la violencia y del extremismo revolucionarios, y no rehuye la metralleta, la bomba ni el atentado". Más adelante, la crítica se dirige hacia la mujer objeto "La mujer-objeto rehuye el serlo; y hace bien; pero no debe ser objeto del hombre objeto, del absurdo play-boy, que tanto abunda, categorizando ante la mujer sin peso, por la serie de conquistas que no tienen nada que conquistar porque están ya conquistadas mil veces." (Consigna, 1975, no 400, p. 53).

Llegados a este punto, cabe preguntarnos ¿qué tipo de mujer debe participar en el espacio público según los discursos de la Sección Femenina? Para intentar responder a esta cuestión, acudiremos a las intervenciones que tuvieron lugar en el acto de inauguración del Año Internacional de la Mujer en Madrid, expuestas en la revista. En primer lugar, a juicio de Pilar Primo de Rivera, la mujer debe tener una situación de igualdad jurídica:

"La mujer en la actualidad puede decirse casi, que no es ya una menor sujeta a tutela, como lo era antes. Dentro de su contextura específica irrenunciable, ha conseguido, por supuesto, enormes conquistas de igualdad con el hombre. No en contra ni enfrente, sino en cuanto a eliminar discriminaciones que le impedían desenvolver sus capacidades, relegadas casi siempre a los exclusivos menesteres caseros o a trabajos secundarios. Ahora la mujer estudia, trabaja, se afana en política, en principio es un miembro igualitario dentro de la sociedad. Esto, más o menos, ya está aceptado." (1975, no 401, p. 45)

Por otra parte, el Director General del Trabajo -Rafael Martínez Emperador- elogiaba la labor realizada por la Sección Femenina en la formación de la mujer española al servicio de la Patria, y mencionaba alguna de sus contribuciones, como: "la propuesta de decisiones legales para regular los derechos políticos, profesionales y laborales del 
sexo femenino, que se concretaron en la Ley de 22 de julio de 1961". Señaló también que en el Proyecto de Ley sobre Relaciones laborales, enviado por el Gobierno a las Cortes "se consagra, en términos absolutos, la igualdad de los derechos, a efectos laborales, de los hombres y de las mujeres, cualquiera que sea el estado civil de éstas". Su intervención terminó con estas palabras: "Se hace preciso recuperar el tiempo perdido para superar la vieja concepción paternalista que relegaba a las mujeres a una función nuevamente pasiva en la vida social, e incorporarlas en su plenitud, por exigencia de la justicia, para participar en todas las tareas que demanda la España que avanza" (Ibidem, p. 48).

El Presidente del Gobierno español, Carlos Arias Navarro, menciona la preocupación por la igualdad de oportunidades entre el hombre y la mujer. Consecuencia de las nuevas sociedades industriales. Realizó una exposición de los logros conseguidos hasta 1975: creación de un Instituto Internacional, el convenio de los Derechos Políticos de la mujer en 1953, la Declaración sobre la eliminación de la dominación sobre las mujeres y, finalmente, el Instituto de la Mujer aprobado en la Asamblea Internacional de Derechos Humanos, de 1968. Con estas medidas, el objetivo que se perseguía conseguir era "instalar en el seno de la sociedad y en nuestras propias conciencias un sentimiento de justicia e igualdad desde los valores inalienables de la persona humana. (Ibidem, p. 49). No dejaron de ser medidas grandilocuentes muy alejadas de la realidad social del momento.

Tendremos que esperar al fin de la dictadura y la transición democrática para ver los resultados que se fueron gestando durante esta década. Nos referimos a la modificación de algunos artículos sobre la situación jurídica de la mujer ${ }^{22}$. En esta última etapa, la Sección Femenina se hace eco de las nuevas medidas legislativas que reconocían ciertos derechos jurídicos a las mujeres casadas, En varios números de la revista Consigna se publicaron una serie de artículos del nuevo Código Civil con sus respectivos comentarios, en cuanto a la nacionalidad (1975, no 407, pp. 51-56); la supresión de la licencia marital, otorgando una mayor igualdad entre los cónyuges (marido y mujer) (1976, no 409, pp. 49-55); sobre el patrimonio que aporta la mujer en régimen matrimonial (1976, no 412, pp. 52-56), y acerca del sistema de capitulaciones en donde se realiza una separación absoluta de bienes de los cónyuges (1976, no 413, pp. 49-55). Se aprecia un cierto interés en dar a conocer los nuevos derechos reconocidos para la mujer casada, que hasta ese momento le habían sido denegados.

En el último año de su existencia, la Sección Femenina organizó una tribuna abierta para tratar la situación de la mujer en la sociedad de ese momento desde distintos ámbitos de participación y representación, como son la política, el trabajo y la familia. La revista realiza una síntesis de las intervenciones protagonizadas por mujeres que alzaron sus voces, reclamando diferentes reivindicaciones.

En relación con la participación de la mujer en la política, se pone de manifiesto la necesidad de una mayor presencia de las mujeres procedentes de las zonas rurales en las tareas políticas, también se reconoce la relación de colaboración entre hombre-mujer en este tipo de actividades: "la mujer debe ayudar al hombre, no ser su enemiga." (1977, $\left.\mathrm{n}^{\circ} 422, \mathrm{p} .28\right)$. Otras intervenciones giraron en torno a las exigencias de tipo legal o jurídico que se demandaban para las mujeres, se plantean nuevas situaciones jurídicas 
como el matrimonio civil, el divorcio, la despenalización del adulterio, la desaparición del concepto de filiación ilegítima, la posibilidad de averiguar la paternidad. Aunque no se muestran a favor del aborto, "opinando que la mejor manera de evitarlo era la de una educación sexual adecuada, que facilitase el control de la natalidad" 23 . También se aprecia un tono más reivindicativo respecto a la discriminación que sufre la mujer por razones de género en el código civil, sobre todo, la mujer casada.

En cuanto a la participación de la mujer en la sociedad de la imagen, la periodista Pilar Urbano -cercana al Opus Dei- se mostró menos partidaria que otras de las ponentes respecto a las responsabilidades y actividades civiles de las mujeres. Para ella, "su responsabilidad es la que la naturaleza le otorga, es decir, ser madre", reivindica como periodista, "volver a poner de moda los valores trascendentales del espíritu" (Ibidem, p. 30).

Destacamos una de las intervenciones más avanzadas que se alzaron sobre la mujer y el trabajo, en la que se denuncia la situación de discriminación injusta hacia la mujer casada. Por otra parte, se evidencian las dificultades que tiene la mujer para alcanzar puestos de responsabilidad en el ámbito laboral que provienen tanto de actitudes de la mujer, la empresa y el hombre como de una defectuosa estructura de la sociedad que frena las oportunidades de la mujer con responsabilidades familiares. La familia, según Mónica Plaza, "es responsabilidad de todos y proteger las circunstancias personales de la mujer no debe ser una concesión graciosa, sino un reconocimiento de su insustituible aportación como madre a la sociedad entera"24 (Idem).

\section{Conclusiones}

A lo largo del franquismo el discurso de la Sección Femenina se fue adaptando a las exigencias políticas que el Nuevo Régimen iba demandando para la formación de la mujer. La construcción del género en la década de los años cuarenta se plantea desde posiciones tradicionales en donde se perfila de forma indisoluble e inseparable la identidad de la mujer ligada a su papel en la familia: será la educadora de los hijos y la perfecta esposa relegada al hogar doméstico, a excepción de la maestra, considerada como una profesión femenina continuadora del hogar.

El desarrollismo demandaba la incorporación de la mujer al mundo laboral, pero sin abandonar su función maternal en un alarde de conseguir la mujer perfecta o superwoman, con la abnegación y sumisión para trabajar dentro y fuera del hogar, propio del discurso patriarcal de esta época. Con cierta continuidad, durante los años cincuenta y sesenta, a pesar de producirse cambios importantes en la propia mentalidad femenina y en una parte de la sociedad, que veía con buenos ojos la incorporación de las mujeres al mundo público, seguían legitimándose aquellas funciones sociales que esta mitad de la población venía desarrollando en el ámbito privado, concretamente en el seno familiar, ligándolas de nuevo al modelo educativo femenino imperante a lo largo de la historia.

Los cambios políticos y sociales que tuvieron lugar en la década de los setenta provocaron una adaptación de los discursos de la Sección Femenina a los nuevos retos de las mujeres, encaminados a una mayor participación en la esfera pública y 
reclamando una mayor igualdad en los ámbitos políticos, jurídicos y laborales. Sin embargo, dicho organismo se encontraba condicionado por las posiciones católicas y tradicionales de su origen, oponiéndose a los planteamientos feministas que reivindicaron la liberación de la mujer desde otras mentalidades ideológicas.

No quisiéramos terminar sin resaltar que a lo largo de estos treinta y siete años de existencia de la revista Consigna, se han podido vislumbrar los discursos que la Sección Femenina articuló para la formación de las mujeres, puesto que dicha publicación se convirtió en un instrumento propagador de su ideología. La importancia y relevancia de la prensa escrita como fuente ha sido muy enriquecedora porque nos ha permitido reconstruir la Historia de la educación de las mujeres desde la categoría de género en una época determinada como fue el franquismo. 


\section{Notas}

1 Se han tenido en cuenta algunos trabajos que utilizan como método de trabajo el análisis de la prensa femenina en la época objeto de estudio. Estas son algunas referencias al respecto: El trabajo de Marina Núñez Gil y Ma José Rebollo Espinosa en el que analizan casi cincuenta revistas dirigidas por organismos afines al régimen franquista (Sección Femenina y Acción Católica) y otras editadas por empresas comerciales, que se inclinan más por contenidos de entretenimiento que por mensajes doctrinales, publicado en 2003: La prensa femenina de postguerra: materiales para la construcción identitaria de la mujer española (A.A.V.V., 2003, pp. 231-246). El reciente trabajo de Miryam Carreño Rivero que analiza en profundidad la revista Chicas dirigida a niñas y adolescentes en la España de postguerra (Carreño, 2003-2004, pp.79-104). También se ha tenido en cuenta el trabajo escrito por Irene Palacio Lis que estudia la revista Consigna durante los primeros diez años de su publicación, pero desde la perspectiva de protección a la infancia y maternidad responsable (Palacio, 2005, pp. 698-709).

2 En relación con los modelos educativos sugeridos a las mujeres en el franquismo puede verse un trabajo realizado anteriormente por una de las autoras (Rabazas, 2001, pp. 423-441).

3 Las autoras de este texto (Mira y Moreno, 2004, p. 324) mencionan los trabajos de (Molinero, 1998, pp. 97-117); (Jiménez, 1982, pp. 77-100) y (Di Febo y Saba, 1986, pp. 439-452).

4 Ley de 17 de julio de 1945 sobre enseñanza primaria. En su art. 11 se establece que "la educación femenina preparará especialmente para la vida del hogar, artesanía e industria domésticas”. (Colección Legislativa, 1944-1945, pp. 838-886).

5 El Concordato de 27 de agosto de 1953 supuso, según Manuel de Puelles,"el reconocimiento del régimen por la Santa Sede y, por tanto, una legitimación exterior, sin reserva alguna, sumnistrada por la Iglesia en cuanto a organización internacional" (1999, p. 324). En el Concordato se regula la enseñanza confesional -ajustándose la enseñanza a los principios del dogma y de la moral de la Iglesia católica (artículo XXVI) - y se garantiza la enseñanza de la religión católica como materia obligatoria y ordinaria en todos los centros docentes (artículo XXVII. ).

6 La revista se compone de diversas secciones, que responden a un interés por desarrollar el mensaje doctrinal de la Sección Femenina. Se inicia con un primer apartado de carácter religioso y con una serie de consignas dirigidas a la práctica escolar que debían seguir las maestras. Le suceden secciones de formación política (Historia de la Falange, discursos de Pilar Primo de Rivera, de José Antonio Primo de Rivera, de Frentes de Juventudes, etc.), de orientación pedagógica (formación pedagógica de las maestras y orientación educativa a las madres), de cultura (historia y literatura que fomentan la España imperial), de hogar (economía doméstica...), música, relatos y obras teatrales, labores, ciudad y campo, actualidad, decoración, divulgación sanitaria, educación física o consultorio del hogar, entre otras, aunque sufren ligeras variaciones en la década de los años sesenta y setenta.

7 En relación con la pedagogía familiar se recogen artículos que orienten a los padres en su labor educativa: formación del carácter, docilidad en el hogar, valor del trabajo, esfuerzo y disciplina, la afectividad, formación de las madres, actitud de las familias ante los resultados escolares de los hijos, las vacaciones escolares (cómo deben orientar los padres el ocio de los hijos), la elección del colegio, etc. Por otra parte, las orientaciones pedagógicas dirigidas a las maestras se centran en aspectos de la práctica escolar: maestras de párvulos, la educación estética femenina, preparación de las clases, enseñanza de la lectura, materias instrumentales y formativas (religión y espíritu nacional), el quehacer escolar y la colaboración familiar (participación de la familia en la formación de los hábitos en los hijos), distribución de las materias y del tiempo, programas oficiales, la preparación de algunos temas del Cuestionario para ingreso en el magisterio nacional, etc. Por último, en relación con la orientación profesional femenina, se proporciona información de las profesiones derivadas de la 
proyección del Hogar en la vida social (aplicaciones del dibujo), cómo se debe elegir una profesión, el porvenir de ciertas profesiones, la iniciación profesional en las zonas rurales y urbanas (labores, corte y confección...), la realización de la persona en el ejercicio de su profesión cuando se ha elegido correctamente, los fundamentos artísticos de la formación profesional en la escuela primaria, etc.

8 Se crearon distintos centros de capacitación para la mujer: "La Escuela Mayor de Mandos José Antonio, en Medina del Campo, instalada en el histórico castillo de La Mota, especialmente donado por el Caudillo para ese fin, y la Escuela de Mandos Isabel la Católica, del Frente de Juventudes, situada en el Pardo, en el edificio denominado La Quinta, destinados a la formación de jerarquías para la Sección Femenina y el Frente de Juventudes. La preparación para el hogar se facilita en las escuelas provinciales...” (Tovar, 1943, p. 30).

9 Véanse los artículos de Francisca Bohigas publicados, en 1944, en la revista Consigna (no 42, pp. 28-31) y (no 37, pp. 17-20).

10 La revista Consigna como instrumento propagador de la Sección Femenina deja entrever en numerosas ocasiones que el lugar de la mujer era el hogar y su misión la maternidad. En este sentido, remitimos a los trabajos de (Gallego, 1983) y (Sánchez, 1990).

11 Para la formación religiosa de la familia y, por supuesto, de las mujeres cristianas se mencionan las siguientes Encíclicas: Encíclica de León XIII "Aranum (matrimonial)”(1880); Encíclica de Pío XI “De la educación cristiana de la juventud”(1929); Encíclica de Pío XI “Quadragesimo Anno”(1931).

12 En este sentido mencionamos algunos decretos laborales y sociales que se dispusieron para imponer una nueva sociedad conservadora, reaccionaria, especialmente con el papel de la mujer en ella. El Fuero del Trabajo de 9 de marzo de 1938, en el capítulo II, art. 1, señala: "En especial prohibirá el trabajo nocturno de las mujeres y los niños, regulará el trabajo a domicilio y libertará a la mujer casada del taller y de la fábrica”. Decreto de 9 de marzo de 1938. Burgos, II Año Triunfal (B.O.E. de 10 de marzo de 1938). Unos meses más tarde, el recién creado Ministerio de Organización y Acción Sindical indicaba órdenes expresas respecto a la mujer trabajadora. Entre sus finalidades pretendía cuantificar la presencia de las mujeres trabajadoras y prever su importancia una vez terminada la guerra, pero dejando claro que: "la tendencia del Nuevo Estado, es que la mujer dedique su atención al hogar y se separe de los puestos de trabajo". Órdenes de 27 de diciembre de 1938. Santander, III Año Triunfal (B.O.E. - Boletín Oficial del Estado- de 31 de diciembre de 1938).

13 Otro dato revelador se manifiesta cuando se critica cómo las mujeres en España no destacan en las carreras industriales, pero a la vez ellas mismas reconocen que "[...] no es que las mujeres tengan un gran quehacer en cualquier rama de la ingeniería, pero hay algunas (Montes, Telecomuniaciones), en las que tal vez podrían desempeñar un buen papel”. (Cajide, 1958, 45-47).

14 Los distintos artículos que la revista Consigna ofrece sobre las mujeres y la política no cesaron en destacar por un lado, las oportunidades políticas que las mujeres estaban adquiriendo en Europa, concretamente en lo que respecta al derecho al voto, pero por otro lado, se las castigaba verbalmente por su atrevimiento. Entre muchos de estos artículos destacamos (Cajide, 1959, pp.43-45); o este otro artículo (Cajide, 1957, pp. 50-52).

15 Dos años más tarde en esta misma revista aparecía otro artículo sobre esta temática en la que se anunciaba haber superado esa situación que limitaba a la mujer "a un dulce papel decorativo", pero añadía que, "éste estaba lleno de sentido y dignidad en algunos casos". (S.J., 1960, p. 1).

16 En la Sección de la revista Consigna titulada Mujeres y la actualidad del mundo observamos cómo hay una interiorización de este modelo de mujer sumisa y resignada, que las propias mujeres debían asumir por imperativo religioso. Un artículo decía lo siguiente: "La mujer, como ven nuestras lectoras, sigue siendo en todas partes el sexo débil, y esto, ¿por qué no decirlo?, nos parece bien, al fin [la negrita es nuestra]. Dios sabe la razón de las cosas y 
cuando consiente que éstas no varíen será porque están mejor sin variar. Después de todo los hombres están hechos para regir y las mujeres para ayudarlos a que rijan lo mejor posible" (Cajide, 1957, pp. 35-36).

17 Un ejemplo de ello es el libro titulado Mistica de la Femineidad escrito por una mujer intelectual, Betty Friedan. (Martínez, 1965, pp. 6-9).

18 Dicho Congreso fue organizado por la Sección Femenina del Movimiento, se celebró en Madrid del 7 al 13 de junio de 1970 y participaron 900 congresistas (hubo representación de 44 países latinoamericanos).

19 Con motivo del XXVII Consejo Nacional de la Sección Femenina del Movimiento, celebrado en Logroño, durante los días 26 al 1 de junio de 1974, se expone entre las conclusiones que este organismo asume la tarea de coordinación para preparar el tema del Año Internacional de la Mujer, auspiciado por la ONU, y que se celebrará en 1975.

20 En este año el movimiento de mujeres se hizo visible en España de múltiples formas, tal y como lo han estudiado los siguientes trabajos citados en (Mira, Moreno, Salas y Comabella, pp. 25-125) y (Folguera, pp. 111-131, cita de pp. 127-128).

21 En la clandestinidad el movimiento feminista comenzó a organizarse entre 1965 y 1975. El Movimiento Democrático de Mujeres (MDM), se creó en 1965, estaba vinculado al Partido Comunista de España. También se alzaron otras voces como la Asociación Democrática de la Mujer, el Colectivo Feminista de Madrid -en torno a Cristina Alberdio el Partido Feminista de Lidia Falcón, entre otros.

22 Nos referimos al nuevo Código Civil y Código de Comercio que fue aprobado en el Pleno de las Cortes el 29 de abril de 1975 y publicado en la Ley de 2 de mayo de 1975 de la Jefatura de Estado.

23 En ese mismo año y dos números antes, se publicó un artículo de un célebre ginecólogo, el Dr. Botella Llusía, que ya escribió en esta revista en los años cuarenta, en donde se argumentan las razones del derecho a la vida y contrarrestan las posiciones a favor del aborto, defendidas por los movimientos feministas: la única vía para la liberación es el control de la esclavitud biológica de la mujer, es decir, pueda liberarse por su propia voluntad del embarazo no deseado, el autor se opone a esta concepción y argumenta su defensa acudiendo a planteamientos teológicos y biológicos (incluso rechaza el aborto en situaciones sospechosas de anormalidad), llegando a vaticinar de forma catastrófica el fin de la humanidad, si la mujer decide negar el derecho a nacer. (1977, no 420, p. 9)

24 Mónica Plaza era consejera nacional y directora del Departamento de Promoción de la mujer de la Sección Femenina del Movimiento.

\section{Referencias}

(1956). Nuestras enseñanzas. Formación Política. Consigna, no 182, pp. 63-65.

(1958). La educación de la mujer. Consigna, no 208, pp. 30-32.

(1959). La preparación para el hogar es una buena asignatura. Consigna, no 218, pp. 43-45.

AA.VV. Etnohistoria de la escuela (pp. pp. 231-246). Actas XII Coloquio Nacional de Historia de la Educación. Burgos: Universidad de Burgos.

Alonso del Real, C. (1943). La mujer en el destino del pueblo. Consigna, no 33, pp. 34-35.

Amoros, C. (1985). Hacia un crítica dela razón patriarcal. Barcelona: Anthropos.

Amoros, M. R.(1966). Efectiva igualdad de los derechos de la mujer española. Familia española, no 81, pp. 48-58.

Azorín, J. (1965). La mujeres en la sociedad moderna. Familia Española, no 64, pp. 11-16. Beauvoir, S. (2000). El segundo sexo. Madrid: Cátedra.

Bel, M. A. (2000). La historia de las mujeres desde los textos. Barcelona: Ariel Practicum.

Benítez, M. J. (1956). Una mujer y un premio Nobel. Consigna, no 189, pp. 37-38.

Bernal, F.J. (1962). La familia en busca de la identidad perdida. Consigna, no 258, pp. 21-26.

Bohigas, F. (1940). Orientación pedagógica. Consigna, no 1, pp. 14-15. 
Bohigas, F. (1941). Ciudad y campo. La maestra rural y las industrias agropecuarias. Consigna, no 2, pp. 24-26.

Bohigas, F. (1941). Orientación pedagógica. A quien corresponde la educación. Consigna, no 4 , pp.11-12.

Bohigas, F. (1941). Orientación pedagógica. Consigna, año I, no 9, pp. 9-10.

Bohigas, F. (1943). La educación ‘̇a quién corresponde?. Consigna, no 34, pp. 20-23.

Bohigas, F. (1943). Orientación pedagógica. Tema XVIII. La educación de la mujer. Consigna, no 29 , pp. 20-23.

Bohigas, F. (1943). Pedagogía del hogar. Consigna, no 31, pp. 20-22.

Bohigas, F. (1944). Educación religiosa. Consigna, no 37, pp. 17-20.

Bohigas, F. (1944). La conciencia nacional. Cómo se forma en el hogar, Consigna, año IV, no 42, pp. 28-31.

Bohigas, F. (1953). Orientación pedagógica. Los fundamentos artísticos de la Iniciación profesional en la Escuela Primaria. Consigna, no 148, pp. 34-37.

Botella Llusía, J. (1943). Peligros de la civilización moderna para la biología de la mujer. Conferencia pronunciada el día 18 de febrero de 1943 por el Dr. José Botella Llusía. Consigna, no 27 , pp. 44-47.

Botella Llusía, J. (1977). El derecho a nacer. Consigna, no 420, pp. 7-13.

Burke, P. (2000). Formas de historia cultural. Madrid: Alianza, Editorial.

Burke, P. (2005). ¿Qué es la historia cultural?. Barcelona-Buenos Aires-Mexico: Piados.

Bussy Genenois, D. (2000). Mujeres en España: de la República al franquismo. Madrid: Taurus.

Cajide, I. (1957). Las mujeres alemanas, italianas y egipcias, en la política. Campañas electoras, promesas de los elegidos y consecuencias de las elecciones. Consigna, no 202, pp. 50-52.

Cajide, I. (1957). Las mujeres en la actualidad del mundo. Consigna, no 192, pp. 29-30.

Cajide, I. (1957). Las mujeres y la actualidad del mundo. De todas las noticias, aun de las más frívolas, pueden sacarse alguna enseñanza. Consigna, no 196, pp.35-36.

Cajide, I. (1957). Noticias de mujeres en la prensa del mundo. Consigna, no 204, pp. 36-37.

Cajide, I. (1958). Las mujeres en el mundo. En España no hay casi "aspirantes" a las Escuelas Especiales. Consigna, no 205, pp.45-47.

Cajide, I. (1958). Las mujeres en el mundo. Las mujeres en la Diplomacia. Consigna, no 206, pp. 47-49.

Cajide, I. (1958). Las mujeres en el mundo. Un porvenir más natural y más luminoso. Consigna, no 208, pp. 41-43.

Cajide, I. (1959). Actualidad. Las mujeres en el mundo. Actividad profesional. Función Pública. Consigna, no 219, pp. 50-52.

Cajide, I. (1959). Actualidad: Las mujeres en el mundo. Las mujeres en el trabajo de Francia. La Policía Femenina de Italia. Las mujeres en Rusia. Consigna, no 220-221, pp. 34-36.

Cajide, I. (1959). La mujer musulmana y su proceso de emancipación. En Suiza las mujeres siguen sin tener derecho al voto. Consigna, no 218, pp. 43-45.

Campos, C. y González, Ma J. (1996). Mujeres y dictaduras en Europa y América: el largo camino. Málaga: Atenea-Universidad de Málaga.

Carreño, M. (2002). La segunda mitad del siglo XX: Análisis sociohistórico y educativo (1950-1990). En AA.VV. La maestra en el proceso de cambio social de transición democrática: espacios histórico generacionales (pp. 87-126). Madrid: Instituto de la Mujer.

Carreño, M. (2003-2004). Chicas en la Postguerra. Un análisis sobre el aprendizaje de género. Historia de la Educación, no 22-23, pp.79-104.

Cavana, Ma L. (1995). Diferencia (pp. 85-118). En Amoros, Celia. 10 palabras clave sobre mujer. Navarra: Verbo Divino.

Cobo Bedía, R. (1995). Género. (pp. 54-83). En Amorós, Celia. 10 palabras clave sobre mujer. Navarra: Verbo Divino.

De Lara, L. (1964). La mujer en veinticinco años de paz española. Familia Española, no 54, pp. 81-88. 
Di Febo, G. y Saba, M. (1986). La condición de la mujer y el papel de la Iglesia en la Italia fascista y en la España franquista: ideologías, leyes y asociaciones femeninas (pp. 439-452). En García-Nieto París, C. (Ed.). Ordenamiento jurídico y realidad social de las mujeres. Siglos XVI-XX. Madrid: Universidad Autónoma,

Fernández Palacios, D. (1961). La familia y el trabajo de la mujer. Familia Española, no 16, pp. 67-68.

Folguera, P. (1988). De la transición política a la democracia. La evolución del feminismo en España durante el periodo 1975-1988 (pp. 111-131). En Folguera, P. (comp.). El feminismo en España: dos siglos de historia. Madrid: Pablo Iglesias.

Gallego Méndez, Ma T. (1983). Mujer, falange y franquismo. Madrid: Taurus.

Hernando, M. P.(1960). Muchachas españolas. Familia Española, no 3, pp. 93-96.

Jaen Sánchez, J. (1959). La orientación profesional femenina. Consigna, no 219, pp. 21-22.

Jiménez Lozanitos, E. (1982). Ideología feminizadota en el franquismo. Orígenes y evolución. En Estudis d'Història Contemporània del País Valencià, no 9, pp. 77-100.

Jover Zamora, J.M.; Gómez-Ferrer, G. y Fusi Aizpúrua, J.P. (2001). España: Sociedad, política y civilización (siglos XIX y XX). Barcelona: Areté.

Juliano, D. (1992). El juego de las astucias. Mujer y construcción de modelos sociales alternativos. Madrid: Horas y horas.

Lazo, M. (1962). Formación de las chicas actuales. Familia Española, no 37, pp. 69-70.

Martínez Medrano, E. (1959). Historia de la Educación Femenina. Consigna, no 223, pp. 31-34.

Martínez Medrano, E. (1965). El feminismo en la actualidad. Consigna, no 289-290, pp. 6-9.

Ministerio de Educación y Ciencia (1972). Colección Legislativa de Educación y Ciencia (años 1944-1945). Madrid: Servicio de Publicaciones del Ministerio de Educación y Ciencia, pp. 838-886.

Ministerio de Educación y Ciencia (1972). Colección legislativa de Educación y Ciencia. (año 1964). Madrid: Servicio de Publicaciones del Ministerio de Educación y Ciencia.

Mira Abad, A. y Moreno Seco, M. (2004). Maternidad y evolución de la identidad femenina en la España del siglo XX (pp. 315-334). En Del Val Valdiviosa y otras (Coords.). La historia de las mujeres: Una revisión historiográfica. Valladolid: Universidad de Valladolid-AEIHM.

Molinero, C. (1998). "Mujer, franquismo, fascismo. La clausura forzada en un mundo pequeño". Historia Social, no 30, pp. 97-117.

Nash, M. (Ed.). (1984). Presencia y protagonismo. Aspectos de la historia de la mujer. Barcelona: Ediciones del Serbal.

Núñez Gil, M. y Rebollo Espinosa, M. J. (2003). La prensa femenina de postguerra: materiales para la construcción identitaria de la mujer española (pp. 231-246). AA.VV. Etnohistoria de la escuela. Actas XII Coloquio Nacional de Historia de la Educación. Burgos: Universidad de Burgos.

Palacio Lis, I. (2005). Protección a la infancia y maternidad responsable en la escuela del Nacional-Catolicismo. La revista Consigna como pretexto (pp. 698-709). En Dávila, P. y Naya, L.M. La Infancia en la historia: Espacios y representaciones. Actas del XIII Coloquio de Historia de la Educación. San Sebastián: Universidad del País Vasco-SEDHE.

Paya Ibars, M. (1959). Temas pedagógicos. Psicopedagogía femenina. Saber ser mamá o prepararse para ser mamá. Consigna, no 225, pp. 7-11.

Paya Ibars, M. R. (1959). Notas sobre psicología femenina: ¿Existe una psicología diferencial por sexos?. Consigna, no 222, pp.13-16.

Paya, R. (1956). Pedagogía Familiar. Consigna, no 183, pp. 33-35.

Paya, R. (1959). Psicopedagogía diferencial femenina: Cómo ven los maestros a las niñas y como se ven ellas. Consigna, no 224, pp.11-14.

Pérez Salabardo, C. (1960). Mujer, familia y trabajo. Familia española, 4, pp. 50-52.

Primo de Rivera, P. (1940). A las maestras falangistas, Consigna, no 1, p.2. 
Puelles Benítez, M. (1999). Educación e ideología en la España contemporánea. Madrid: Tecnos.

Rabazas Romero, T. (2001). Modelos de mujer sugeridos a las maestras en el franquismo. Bordón, no 53 , pp. 423-441.

Ramírez, M. (1978). España 1939-1975. Régimen político e ideología. Barcelona: Labor.

Ramos, M.P. (1956). Formación Familiar y Social. Consigna, no 182, pp. 67-70.

Rubio Mora, S. (1965). La iniciación profesional femenina. Consigna, no 292, pp. 11-14.

Ruiz Berrio, J. (2000). Nuevos enfoques en la historia del pensamiento pedagógico (pp.271-295). En Ruiz Berrio, J. (Ed.) La cultura escolar de Europa. Nuevas tendencias emergentes. Madrid: Biblioteca Nueva.

Salas, M. y Comabella, M. (1999). Asociaciones de mujeres y movimiento feminista (pp. 25-125). En Asociaciones de mujeres en la transición democrática: Españolas en l a transición. De excluidas a protagonistas (1973-1982). Madrid: Biblioteca Nueva.

S.J. (1960). La mujer en primer plano. Consigna, no 267, pp. 1-2.

Sánchez López, R. (1990). Mujer española. Una sombra de destino en lo universal. Trayectoria histórica de la Sección Femenina de Falange (1934-1974). Murcia: Universidad de Murcia.

San Román, S.; Anula Alameda, J. J. (2002). Espacios histórico generacionales de la maestra en el proceso de cambio social hacia la transición democrática (pp. 208-322). En AA.VV. La maestra en el proceso de cambio social de transición democrática: espacios histórico generacionales. Madrid: Instituto de la Mujer.

Torbado, J. (1965). La mujer en el Japón. Familia Española, no 70, pp. 74-78.

Tovar, A. (1943). Actualidad. Esperanza del 18 de julio. Consigna, año III, no 30, p. 28. Tschudowsky, N. (1965). Ellas hablan de ellos. Familia Española, no 68, pp. 43-47.

Young, M. (1965). Cada vez es mayor la participación de las mujeres en la vida pública británica. Familia Española, no 70, pp. 25-29. 